\title{
Mekanisme Pengawasan terhadap Lalu Lintas Barang Masuk ( Impor ) dan Barang Keluar ( Ekspor) pada Kantor Pengawasan dan Pelayanan Bea dan Cukai Type Madya Pabean C Mataram \\ Mintasrihardi' ${ }^{1}$, Baiq Reinelda ${ }^{2}$, Elisyah ${ }^{3}$
}

1Prodi Administrasi Publik, Universitas Muhammadiyah Mataram , Indonesia

2Prodi Administrasi Bisnis, Universitas Muhammadiyah Mataram, Indonesia

3Prodi Administrasi Publik, Universitas Muhammadiyah Mataram, Indonesia

\section{INFO ARTIKEL}

Riwayat Artikel:

Diterima: $10-02-2018$

Disetujui: 11-03-2018

\section{Kata Kunci:}

1. Pengawasan

2. Ekspor

3. Impor

4. Kepabeanan

\begin{abstract}
ABSTRAK
Abstrak: Perdagangan Internasional dilakukan oleh semua Negara di Dunia termasuk Indonesia. Indonesia melakukan perdagangan internasional dengan kegiatan ekspor impor barang. Manfaat dilakukannya kegiatan ini salah satunya menambah penerimaan negara. Setiap kegiatan ekspor impor barang akan menimbulkan kewajiban kepabeanan. Secara teknis, proses importasi melibatkan banyak kepentingan atau pihak, baik itu kegiatan-kegiatan sebelum barang tiba, proses pada saat barang tiba, proses customs clearence, hingga pada proses pengeluaran barang tiba. Sebaik apapun sistem yang digunakan apabila tidak didukung oleh aparat yang bersih atau profesional ditambah oleh pihak-pihak yang berusaha memanfaatkan kelemahan peraturan yang ada untuk kepentingan pribadi, tentunya sistem tersebut tidak akan bisa berjalan dengan baik atau malah sia-sia. Dalam hal ini, diperlukan pengawasan yang efektif kepada aparat bea dan cukai dalam melaksanakan tugas pengawasan lau lintas barang tersebut.Tujuan penelitian ini untuk mendeskripsikan mekanisme pengawasan terhadap ekspor dan impor barang dan untuk mengetahui faktor apa saja yang mempengaruhi pengawasan kepabeanan.
\end{abstract}

Penelitian ini adalah penelitian kualitatif dengan pendekatan deskriptif. Dalam hal ini peneliti mendedkripsikan mekanisme pengawasan terhadap lalu lintas barang ekspor dan impor yang dilakukan oleh Bea dan Cukai Mataram. Oleh karena itu peneliti melakukan observasi dan wawancara kemudian menganalisisnya dengan pengumpulan data, reduksi data,display data, dan penarikan kesimpulan.

Dari hasil analisis tersebut diperoleh bahwa mekanisme pengawasan terhadap lalu lintas ekspor impor yang dilakukan oleh KPPBC TMP C mataram sudah sesuai dengan peraturan perUndang-Undangan dimulai dari pengumpulan informasi dari intelijen, penelitian dokumen, pemeriksaan fisik, penetapan jalur terhadap barang yang melewati daerah pabean serta melaporkan hasil pengawasan kepada pusat dengan rutin.

\section{Abstract}

International Trade is conducted by all countries in the World including Indonesia. Indonesia conducts international trade with export goods import activities. The benefits of doing this activity one of them increase the state revenue. Any export activity of imported goods will result in customs duties. Technically, the importation process involves a lot of interests or parties, be it activities before the goods arrive, the process at the time of the goods arrived, the process of customs clearence, until the goods release process arrived. As good as any system that is used if it is not 
Keyword:

1. Supervision

2. Export

3. Import

4. Customs supported by a clean or professional apparatus plus parties who try to take advantage of existing regulatory weaknesses for personal benefit, of course the system will not be able to run well or even in vain. In this case, effective supervision of customs and customs authorities in carrying out the monitoring tasks of the goods. The purpose of this study is to describe the monitoring mechanisms on the export and import of goods and to determine what factors influence the control of customs.

This research is qualitative research with descriptive approach. In this case the researcher describes the monitoring mechanism to the traffic of export and import goods conducted by Customs and Excise of Mataram. Therefore, researchers conducted observations and interviews then analyzed it with data collection, data reduction, data display, and conclusions.

From the analysis result, it is found that the monitoring mechanism to import export traffic conducted by KPPBC TMP $C$ mataram is in accordance with the rules of invitation begins with gathering information from intelligence, document research, physical inspection, determining the path to goods passing through customs area and reporting supervision results to the center on a regular basis.

\section{Latar Belakang}

Perdagangan Internasional dilakukan oleh semua negara di dunia termasuk Indonesia. Indonesia melakukan perdagangan internasional dengan kegiatan ekspor impor barang. Manfaat dilakukannya kegiatan ini salah satunya menambah penerimaan negara. Setiap kegiatan ekspor impor barang akan menimbulkan kewajiban kepabeanan. Beberapa kewajiban tersebut adalah pembayaran bea masuk, bea keluar dan pajak. Berdasarkan data yang diperoleh dari kemenkeu.go.id, pada tahun 2017 penerimaan negara yang berasal dari bidang kepabeanan menyumbang sebesar $12 \%$ dari pendapatan negara. Hal ini menunjukkan bahwa bidang kepabeanan ikut berperan dalam penerimaan negara oleh karena itu perlu untuk dilakukan pengawasan.

Institusi yang berwenang untuk melaksanakan tugas pengawasan di bidang kepabeanan adalah Direktorat Jenderal Bea dan Cukai (DJBC). Pengawasan yang dilakukan oleh DJBC merupakan langkah untuk mengoptimalkan penerimaan negara yang berasal dari bidang kepabeanan. Pengawasan ini dilakukan karena diterapkannya self assesment system dalam pemenuhan kewajiban kepabeanan. Instansi vertikal DJBC yang menjalankan tugas pengawasan atas kegiatan ekspor impor barang adalah Kantor Pengawasan dan Pelayanan Bea dan Cukai (KPPBC).

Undang- Undang Nomor 10 Tahun 1995 tentang Kepabeanan mulai diberlakukan pada tanggal 1 Maret 1997. Karena adanya tuntutan dan masukan dari masyarakat untuk dilaksanaakannya revisi terhadap Undang Undang Nomor 10 Tahun 1995 Tentang Kepabeanan. Ini merupakan wujud nyata dari kurangnya antisisipasi dari pihak-pihak terkait dalam konstruksi hukum kepabeanan Indonesia. Di lain pihak, perkembangan modifikasi norma hukum bagi pengaturan perdagangan internasional semakin pesat. Oleh karena itu, situasi yang dihadapi oleh sumber daya manusia di lingkungan kepabeanan Indonesia semakin tertinggal dalam upaya mengikuti arus perkembangan pemikiran ekonomi perdagangan internasional, apalagi dalam upaya memberikan sumbangan pemikiran. Tujuan perubahan Undang-Undang Nomor 10 Tahun 1995 Tentang Kepabeanan menjadi Undang-Undang Nomor 17 Tahun 2006 Tentang Kepabeanan adalah untuk lebih menjamin kepastian hukum, keadilan, transparansi dan akuntabilitas pelayanan publik, mendukung upaya peningkatan dan pengembangan perekonomian nasional yang berkaitan dengan perdagangan global, mendukung kelancaran arus barang dan meningkatkan efektivitas pengawasan atas lalu lintas barang yang masuk atau keluar daerah 
pabean Indonesia dan lalu lintas barang tertentu dalam daerah pabean Indonesia, serta mengoptimalkan pencegahan dan penindakan penyelundupan.

Berdasarkan artikel dikutip dalam suarantb.com (2017) bahwa Bea cukai Mataram menerima kunjungan dari Kepala Dinas Perdagangan Provinsi NTB, Dra. Hj. Selly Andayani, M.Si dan jajaran dan Dinas Tenaga Kerja Transmigrasi (Disnakertrans) Provinsi NTB. Kunjungan tersebut dalam rangka membangun sinergi untuk memberikan pemahaman kepada masyarakat tentang aturan yang ditetapkan pemerintah. Seperti diketahui, larangan membawa Hand Phone lebih dari dua buah dari luar negeri, diatur dalam Peraturan Menteri Perdagangan (Permendag ) Nomor 38 Tahun 2013 tentang Perubahan Atas Peraturan Menteri Perdagangan Nomor 82/2012 tentang Ketentuan Impor Telepon Seluler, Komputer Genggam dan Komputer Tablet. Regulasi tersebut mengatur tentang pembatasan maksimal barang elektronik yang dibawa masuk kedalam negeri. Berdasarkan data yang diperoleh dari seksi penindakan dan penyidikan KPPBC TMP C Mataram pada pertengahan tahun 2017 pelanggaran yang terjadi di bidang kepabeanan adalah sebanyak 150 kasus pelanggaran. Jenis pelanggaran yang terjadi antara lain, penyelundupan pemberitahuan jumlah dan/ atau jenis pos tarif Harmonized System (HS) yang salah, pemberitahuan jumlah dan jenis yang tidak sesuai dengan uraian barang, mengimpor barang yang merupakan barang larangan atau pembatasan, mengimpor barang yang tidak tercantum dalam manifes. Jenis pelanggaran ini tentu akan mengganggu penerimaan negara dan kerugian lain bagi negara. Adapun kasus atau kejadian yang terjadi di lingkungan KPPBC Mataram adalah banyaknya jumlah impor hand phone baik melalui jasa pengiriman pos maupun barang yang di bawa oleh penumpang melalui Bandar Udara yang sering kali melanggar peraturan Permendag tentang batas maksimal pemasukan barang tersebut. Kasus selanjutnya adalah pada Customs Declaration yang diisi oleh penumpang tidak sesuai dengan barang bawaan, sering kali petugas bea dan cukai menemukan barang larang dan batasan seperti minuman beralkohol lebih dari 1 liter, membawa binatang peliharaan, membawa alat kesehatan dalam jumlah berlebih, membawa narkotika, dan lainnya yang tidak dicantumkan pada dokumen. Oleh karena itu KPPBC Tipe
Madya Pabean C Mataram harus lebih meningkatkan pengawasannya agar tidak terjadi pelanggaran kepabeanan dan dapat lebih mengoptimalkan penerimaan negara yang berupa bea masuk, bea keluar dan pajak serta mencegah kerugian bagi negara lainnya.

Secara teknis, proses importasi melibatkan banyak kepentingan atau pihak, baik itu kegiatan-kegiatan sebelum barang tiba, proses pada saat barang tiba, proses customs clearence, hingga pada proses pengeluaran barang tiba. Sebaik apapun sistem yang digunakan apabila tidak didukung oleh aparat yang bersih atau profesional ditambah oleh pihak-pihak yang berusaha memanfaatkan kelemahan peraturan yang ada untuk kepentingan pribadi, tentunya sistem tersebut tidak akan bisa berjalan dengan baik atau malah sia-sia. Dalam hal ini, diperlukan pengawasan yang efektif kepada barang ekspor maupun impor oleh bea dan cukai dalam melaksanakan tugas pengawasan lau lintas barang tersebut.

Berdasarkan uraian latar belakang maka penting kiranya melakukan penelitian bagaimana mekanisme pengawasan pabean tehadap arus masuknya barang (Impor) dan barang keluar (Ekspor) sehingga dapat mengoptimalkan penerimaan Negara dan meminimalisir pelanggaran yang sering terjadi dan di implementasikan berdasarkan peraturan peraturan perundang-undangan yang belaku di Indonesia.

\section{Tinjauan Pustaka}

\section{a. Administrasi Publik}

Definisi Administrasi Publik menurut Chandler dan Plano dalam Pasolong, Harbani (2011:7), mengatakan bahwa Administrasi Publik adalah proses dimana Sumber Daya dan personel Publik diorganisir dan dikoordinasikan untuk memformulasikan, mengimplementasikan, dan mengelola (manage) keputusan-keputusan dalam Kebijakan Publik. Konsep Administrasi Publik di Indonesia pada dasarnya bukanlah konsep yang baru, karena konsep administrasi Publik sudah ada sejak dari dulu, hanya para pakar yang mengganti istilah Administrasi Publik menjadi Administrasi Negara. Begitu pula buku-buku asing misalnya yang berjudul "Public Adminitration" diganti menjadi Administrasi Negara. Jika ada para pakar yang mengatakan bahwa Administrasi Negara perlu direformasi menjadi Administrasi Publik, maka itu dapat dikatakan kesalahan 
berfikir, karena Administrasi Publik sudah ada sejak dari dulu. (Pasolong, 2012:55).

Chandler \& Plano dalam Pasolong (2012:55), menjelaskan bahwa Administrasi Publik merupakan Seni dan Ilmu yang ditujukan untuk mengatur "Publik Affairs" dan melaksanakan berbagai tugas yang ditentukan. Administrasi Publik sebagai disiplin ilmu bertujuan untuk memecahkan Masalah Publik melalui perbaikan-perbaikan terutama dibidang organisasi, sumberdaya manusia dan keuangan. Menurut Nicholas Hendry dalam Pasolong (2012:56) mendefinisikan "Administrasi Publik adalah suatu kombinasi yang kompleks antara teori dan praktik, dengan tujuan mempromosikan pemahaman terhadap pemerintah dalam hubungannya dengan masyarakat yang diperintah, dan juga mendorong kebijakan publik agar lebih responsif terhadap kebutuhan sosial".

George J. Gordo dalam Inu Kencana, (51:2015) Administrasi Publik dapat dirumuskan sebagai seluruh proses yang baik yang dilakukan organisasi maupun perseorangan yang berkaitan dengan penerapan atau pelaksanaan hukum dan peraturan yang dikeluarkan oleh badan legislatif, eksekutif serta peradilan. Administrasi Publik dimaksudkan untuk lebih memahami hubungan pemerintah dengan publik serta meningkatkan responbilitas kebijakan terhadap berbagai kebutuhan publik, dan juga melembagakan praktik-praktik manajerial agar terbiasa melaksanakan suatu kegiatan dengan efektif, efisien dan rasional.

Beberapa definisi Administrasi Publik yang telah dikemukakan oleh para ahli di atas, dapat dipahami bahwa Administrasi Publik adalah kerjasama yang dilakukan oleh sekelompok orang atau lembaga dalam melaksanakan tugas-tugas pemerintahan dalam memenuhi kebutuhan publik secara efesien dan efektif.

\section{b. Pengertian Pengawasan}

Menurut Sutedi

(2012:58-59)

pengawasan adalah suatu kegiatan untuk menjamin atau menjaga agar rencana dapat diwujudkan dengan efektif. Masing-masing organisasi mempunyai rencana untuk mencapai tujuan yang telah ditetapkan. Untuk menjaga agar organisasi itu dapat mencapai tujuannya, mutlak diperlukan pengawasan. Menurut Rahmadi (2006:194), rencana merupakan bagian tak terelakkan dalam suatu organisasi sebagai tahap awal untuk pencapaian tujuan. Sedangkan berdasarkan Peraturan Direktorat Jenderal (PerDirJen) Bea dan Cukai Nomor P-53/BC/2010 tentang Tata Laksana Kepabeanan menjelaskan bahwa pengawasan adalah "keseluruhan kegiatan pengawasan kepabeanan dan cukai yang meliputi kegiatan intelijen, penindakan, penanganan perkara, intelijen dan penindakan Narkotika, Psikotropika dan Prekursor Narkotika dan pengelolaan sarana operasi”. Siagiaan (2012: 259) pengawasan dilakukan berfungsi untuk mencegah terjadinya ketidaksesuaian rencana dengan kegiatan yang sedang berlangsung.

Menurut Saidi (2011:70), Bentuk pengawasan dalam rangka pengelolaan dan tanggung jawab keuangan negara dapat berupa:

1. Pengawasan yang dilakukan oleh atasan terhadap bawahannya dalam suatu lingkungan kerja.

2. Pengawasan yang dilakukan oleh Inspektorat jenderal, Inspektorat Provinsi, dan Inspektorat Kabupaten / Kota.

3. Pengawasan yang dilakukan oleh Badan Pengawasan Keuangan dan Pembangunan.

4. Pengawasan yang dilakukan oleh Badan Pemeriksa Keuangan.

Menurut Situmorang ( 1998:27), dalam suatu negara terlebih-lebih dalam negara yang sedang berkembang atau membangun, maka kontrol / pengawasan sangat urgent atau penting baik pengawasan secara vertikal, horizontal, eksternal, internal, preventif maupun represif agar maksud atau tujuan negara atau organisasi, maka dalam hal ini pengawasan ini dapat pula di klasifikasikan macam-macam pengawasan berdasarkan sifatnya, yakni :

1. Pengawasan Langsung dan Pengawasan Tidak Langsung

a. Pengawasan Langsung

Pengawasan langsung adalah pengawasan yang dilakukan secara pribadi oleh pimpinan atau pengawas dengan mengamati, meneliti, memeriksa, mengecek sendiri di tempat pekerjaan dan menerima laporanlaporan secara langsung pula dari pelaksana. Hal ini dilakukan dengan inspeksi.

b. Pengawasan Tidak Langsung 
Pengawasan tidak langsung diadakan dengan mempelajari laporanlaporan yang diterima dari pelaksana baik lisan maupun tertulis, mempelajari pendapat-pendapat masyarakat dan sebagainya.

2. Pengawasan Preventif dan Pengawasan Represif

a. Pengawasan Preventif

Dilakukan melalui preaudit sebelum pekerjaan dimulai. Misalnya dengan mengadakan pengawasan terhadap persiapan-persiapan, rencana kerja, rencana anggaran, rencana penggunaan tenaga dan sumber-sumber lain.

b. Pengawasan Represif

Dilakukan melalui post-audit,
dengan pemeriksaan $\begin{array}{r}\text { terhadap } \\ \text { (inspeksi), }\end{array}$
pelaksanaan ditempat pelaksanaan dan
meminta laporan pan
sebagainya.

3. Pengawasan Intern dan Pengawasan Ekstern

a. Pengawasan Intern

Pengawasan Intern adalah pengawasan yang dilakukan oleh aparat dalam organisasi itu sendiri. Pada dasarnya pengawasan harus dilakukan oleh pimpinan sendiri.

b. Pengawasan Ekstern

Pengawasan Ekstern adalah pengawasan yang dilakukan oleh aparat di luar organisasi itu sendiri.

Adapun macam-macam pengawasan yang tercantum dalam Lampiran Instruksi Presiden Republik Indonesia Nomor 1 Tahun 1989 tentang Pedoman Pelaksanaan Pengawasan Melekat yakni:

1. Pengawasan Melekat

Pengawasan melekat dalah serangkaian kegiatan yang bersifat sebagai pengendalian yang terus menerus, dilakukan oleh atasan langsung terhadap bawahannya, secara preventif atau represif agar pelaksanaan tugas bawahan tersebut berjalan secara efektif dan efisien sesuai dengan rencana kegiatan dan peraturan perundang-undangan yang berlaku.

2. Pengawasan Fungsional
Pengawasan fungsional adalah pengawasan yang dilakukan oleh aparat pengawasan secara fungsional baik intern pemerintah maupun ekstern pemerintah, yang dilaksanakan terhadap pelaksanaan tugas umum pemerintahan dan pembangunan agar sesuai dengan rencana dan peraturan perundangundangan yang berlaku.

3. Pengawasan Masyarakat

Pengawasan

masyarakat pengawasan yang dilakukan oleh warga masyarakat yang disampaikan secara lisan atau tertulis kepada aparatur pemerintah yang berkepentingan, berupa sumbangan pikiran, saran, gagasan, atau keluhan/pengaduan yang bersifat membangun yang disampaikan baik secara langsung maupun melalui media.

4. Pengawasan Legislatif

Pengawasan legislative adalah pengawasan yang dilakukan oleh lembaga perwakilan rakyat terhadap kebijaksanaan dan pelaksanaan tugastugas umum pemerintahan dan pembangunan.

\section{c. Pajak, Bea dan Cukai Lalu Lintas Barang dalam Kepabeanan}

Pengertian pajak menurut Bohari (2012:25) adalah iuran rakyat kepada negara berdasarkan undang-undang (dapat dipaksakan), yang langsung dapat ditunjuk atau digunakan untuk membiayai pembangunan. Pengertian Pajak atas lalu lintas barang adalah sebagai pungutan negara atas pemasukan dan pengeluaran barang ke dalam maupun keluar daerah pabean yang terutang oleh pengguna jasa kepabeanan saat barang melintasi batas negara Indonesia.

Melewati batas-batas negara atau dari pulau satu ke pulau lain di dalam daerah. Pajak atau bea yang dipungut atas lalu lintas barang impor berupa bea masuk, pajak pertambahan nilai, pajak penghasilan. Sedangkan untuk barang-barang ekspor adalah bea keluar.

Kepabeanan dalam Pasal 1 angka 1 Undang-Undang Nomor 17 Tahun 2006 Tentang Perubahan atas Undang-Undang Nomor 10 Tahun 1995 Tentang Kepabeanan adalah : 
"Kepabeanan adalah segala sesuatu yang berhubungan dengan pengawasan lalu lintas barang yang masuk atau keluar daerah pabean serta pemungutan bea masuk dan bea keluar."

Menurut Putra (2009:40) Barang yang termasuk dalam barang jenis barang larangan dan pembatasan pemasukan dan pengeluarannya ke atau dari wilayah Republik Indonesia tanpa ijin dari instansi berwenang adalah:

1) Narkotika ( Narcotics )

2) Bahan peledak ( Explosive materials )

3) Petasan (Fire works )

4) Senjata api dan amunisi ( fire arm and ammunition )

5) Psikotropika ( Psychotropics )

6) Buku dengan barang cetakan tertentu (Defined books and printed materials)

7) Media rekam audio dan / atau visual ( Audio and/or Visual recording media)

8) Alat-alat telekomunikasi (Telecommmunication equipment)

9) Mesin fotocopi berwarna, bagian / suku cadang dan peralatannya (Colour photo Copy, parts and equipment therenf)

10) Beberapa jenis tumbuhan dan satwa liar yang dilindungi serta bagian- bagiannya (Undangered species of wild fauna and flora, and parts therenf) .

11) Beberapa jenis ikan tertentu (Certain species of fish)

12) Makanan dan minuman yang tidak terdaftar pada Departemen Kesehatan RI (Unregistered food and beverages at The Departement of Health)

13) Obat-obatan (medicines)

14) Bahan-bahan berbahaya (Dangerous materials)

15) Pestisida (Pesticides)

16) Bahan perusak lapisan ozon dan barang yang menggunakan bahan perusak lapisan ozon (Ozonedepicting substances and goods containing ozone depleting substances )

17) Limbah ( Wastes )

18) Benda cagar budaya ( Cultural valuable goods )

19) Produk tertentu ( Certain products )

20) Uang rupiah dengan jumlah tertentu (Certai amount of rupiah in cash)

d. Tipe Pelanggaran Kepabeanan (bidang pengecekan keluar dan masuk barang)
Menurut Sutarto

(2010:103) pelanggaran pabean sebagaimana dimaksud dalam konvensi Kyoto adalah "Customs offence, means any breach, or attempted breach of custom law" (pelanggaran pabean adalah setiap pelanggaran, atau percobaan pelanggaran, terhadap UU pabean). Pelanggaran dimaksud dikelompokkan ke dalam dua kelompok yakni pelanggaran ketentuan administrasi yang dikenakan sanksi administrasi berupa denda yang besarannya tercantum ketentuan perundang-undangan serta penerapannya diatur dalam peraturan pemerintah tentang sanksi administrasi.Yang kedua adalah pelanggaran ketentuan pidana yang ancaman pidananya diatur dalam ketentuan perundang-undangan dan diproses sesuai hukum acara pidana.

Dalam buku Sutarto (2010:103) Pelanggaran pabean menurut WCOHandbook for commercial Fraud Investigators dipilah menjadi enam belas tipe pelanggaran utama di bidang kepabeanan, yaitu sebagai berikut :

1. Penyelundupan

2. Uraian barang tidak benar

3. Pelanggaran nilai barang

4. Pelanggaran negara asal barang

5. Pelanggaran fasilitas keringanan bea masuk atas barang yang diolah

6. Pelanggaran impor sementara

7. Pelanggaran perizinan ekspor/impor

8. Pelanggaran transit barang

9. Pemberitahuan jumlah muatan barang tidak benar

10. Pelanggaran spesifikasi barang dan perlindungan konsumen

11. Barang melanggar hak atas kekayaan intelektual

12. Transaksi gelap

13. Pelanggaran pengembalian bea

14. Usaha fiktif

15. Likuidasi palsu

\section{Metode Penelitian}

Penelitian ini adalah penelitian kualitatif dengan pendekatan deskriptif. Penelitian kualitatif adalah penelitian yang bermaksud untuk memahami fenomena tentang apa yang dialami oleh subjek penelitian secara holistik, dan dengan cara deskripsi dalam bentuk katakata dan bahasa pada suatu konteks khusus yang alamiah dan dengan memanfaatkan berbagai metode alamiah (Moleong, 2011:6). 
Penelitian ini dilaksanakan pada Kantor Pengawasan dan Pelayanan Bea dan Cukai Tipe Madya Pabean C Mataram.

Sumber data dalam penelitian ini adalah data primer yang merupakan data yang diperoleh dari hasil pengamatan langsung (observasi) dengan pihak-pihak terkait. Dalam hal ini pegawai Kantor Pengawasan dan Pelayanan Bea dan Cukai Tipe Madya Pabean C Mataram khususnya pada Seksi Penindakan dan Penyidikan (P2) dan Seksi Pelayanan Kepabeanan dan Cukai dan Dukungan Teknis (PKCDT) yang terkait dengan penelitian ini.

Untuk mengumpulkan data yang dibutuhkan dalam penulisan ini maka digunakan pengumpulan data sebagai berikut :

1. Penelitian Lapangan (Field Research)

a. Pengamatan (Observasi)

b. Wawancara (Interview)

Teknik analisa data yang digunakan dalam penelitian ini adalah analisis data kualitatif, mengikuti konsep yang diberikan Miles dan Huberman. Miles dan Huberman dan Saldana (2014), mengemukakan bahwa aktifitas dalam analisis data kualitatif dilakukan secara interaktif dan berlangsung secara terus menerus pada setiap tahapan penelitian sehingga sampai tuntas, dan datanya sampai jenuh. Aktivitas dalam analisis data, yaitu data reduction, data display, data reduction, dan conclusion drawing/verification.

\section{Hasil dan Pembahasan}

a. Mekanisme Pengawasan Lalu Lintas Barang pada Kantor Pengawasan dan Pelayanan Bea dan Cukai Tipe Madya Pabean C Mataram

Pengawasan yang dilakukan oleh Kantor Pengawasan dan Pelayanan Bea dan Cukai Tipe Madya pabean C Mataram atau biasa disebut KPPBC Mataram, ada pengawasan barang masuk ( impor ) baik impor umum maupun impor yang dibawa oleh penumpang dan paketan melalui jasa POS dan barang keluar ( ekspor ) yang disini skalanya cukup kecil yang disebabkan oleh beberapa faktor yaitu sakala penerbangan yang hanya terdiri dari dua asal negara yaitu Malaysia dan Singapura. Untuk paket Pos itu sendiri kebanyakan barang kiriman TKI yang bekerja di luar negeri. Adapun mekanisme pengawasan yang dilakukan oleh pejabat bea cukai baik ekspor dan impor adalah sebagai berikut :

\section{a) Mekanisme Pengawasan terhadap Barang Masuk ( Impor )}

Pengawasan impor barang dilakukan oleh Seksi Kepabeanan dan Seksi Penindakan dan Penyidikan (P2). Pengawasan barang impor yang dilakukan oleh KPPBC TMP C Mataram sudah sesuai dengan PerDirjen Bea dan Cukai Nomor P-53/BC/2010 tentang Tata Laksana Pengawasan. Dalam pelaksanaan tugas pengawasan, KPPBC TMP C Mataram juga telah menerapkan jalur-jalur pengawasan untuk melihat sejauh mana akan dilakukan pengawasan terhadap barang tersebut. Kemudian mekanisme melalui CEISA (Customs- Excise Information System and Automation) untuk penetapan jalur lalu lintas barang untuk warna merah biasanya untuk importir baru yang memiliki risiko tinggi (high risk) dan dilakukan pemeriksaan fisik. Setelah sistem terbaca merah maka

\begin{tabular}{|c|c|c|c|c|}
\hline $\begin{array}{r}\text { Tang } \\
\text { gal }\end{array}$ & Lokasi & Komoditi & $\begin{array}{r}\text { Jumlah dan } \\
\text { Jenis } \\
\text { Barang }\end{array}$ & $\begin{array}{r}\text { Aturan Larangan dan } \\
\text { Batasan }\end{array}$ \\
\hline $\begin{array}{r}11- \\
\text { Jan- } \\
16\end{array}$ & $\begin{array}{c}\text { Kantor } \\
\text { Pos }\end{array}$ & $\begin{array}{r}\text { 15. Barang Lartas } \\
\text { lainnya }\end{array}$ & $\begin{array}{r}63 \text { pcs } \\
\text { Syringe }\end{array}$ & $\begin{array}{r}\text { Permenkes no.1190/ } \\
\text { Menkes/ per/ VIII/ } 2010 \\
\text { ttg izin edar alat kesehatan } \\
\text { dan perbekalan kesehatan } \\
\text { rumah tangga }\end{array}$ \\
\hline $\begin{array}{r}29- \\
\text { Jan- } \\
16\end{array}$ & Bil & $\begin{array}{r}9 \text { Sejata dan } \\
\text { Bahan } \\
\text { peledak }\end{array}$ & $\begin{array}{r}2 \text { pcs } \\
\text { senjata } \\
\text { tajam }\end{array}$ & $\begin{array}{r}\text { Perpu 20/1960 jo. Kep. } \\
\text { Kapolri no. } \\
\text { Skep/82/ii/2004 jo. } \\
\text { R/13/i/2005 }\end{array}$ \\
\hline $\begin{array}{r}29- \\
\text { Jan- } \\
16\end{array}$ & Bil & 11. Cites & $\begin{array}{r}3 \text { ekor } \\
\text { burung }\end{array}$ & $\begin{array}{r}\text { Peraturan Pemerintah } \\
\text { Nomor } 82 \text { Tahun } 2000 \\
\text { tentang Karantina Hewan }\end{array}$ \\
\hline $\begin{array}{r}29- \\
\text { Feb- } \\
16\end{array}$ & BIL & $\begin{array}{r}\text { 15. Barang Lartas } \\
\text { Lainnya }\end{array}$ & $\begin{array}{r}12 \text { pcs } \\
\text { burung }\end{array}$ & $\begin{array}{r}\text { Peraturan Pemerintah } \\
\text { Nomor } 82 \text { Tahun } 2000 \\
\text { tentang Karantina Hewan }\end{array}$ \\
\hline $\begin{array}{r}31- \\
\text { Mei- } \\
16\end{array}$ & Bil & $\begin{array}{l}\text { 10. Obat-obatan } \\
\text { \& Bahan Kimia }\end{array}$ & $\begin{array}{r}6 \text { pk Obat } \\
\text { Obatan }\end{array}$ & $\begin{array}{r}\text { Peraturan Kepala Badan } \\
\text { POM No. } 12 \text { Tahun } 2015 \\
\text { tentang Pengawasan } \\
\text { Pemasukan Obat dan } \\
\text { Makanan ke Dalam } \\
\text { Wilayah Indonesia }\end{array}$ \\
\hline $\begin{array}{r}30- \\
\text { Jun- } \\
16\end{array}$ & $\begin{array}{l}\text { Kantor } \\
\text { POS }\end{array}$ & $\begin{array}{l}\text { 10. Obat-obatan } \\
\text { \& Bahan Kimia }\end{array}$ & $\begin{array}{r}6 \mathrm{Pk} \\
\text { Kosmetik }\end{array}$ & $\begin{array}{r}\text { Peraturan Kepala Badan } \\
\text { POM No. } 12 \text { Tahun } 2015 \\
\text { tentang Pengawasan } \\
\text { Pemasukan Obat dan } \\
\text { Makanan ke Dalam } \\
\text { Wilayah Indonesia }\end{array}$ \\
\hline
\end{tabular}

keluar SPJM (Surat Pemberitahuan Jalur Merah) kemudian pihak bea cukai menunjuk pelaksana pemeriksa untuk memeriksa barang tersebut. Setelah dibongkar maka hasil pemeriksaan tersebut 
di upload untuk diteliti oleh atasan. Apabila tidak disetujui maka tambah bayar, apabila disetujui maka diterbitkan SPPB (Surat Persetujuan Pengeluaran Barang) maka selanjutnya barang tersebut dapat keluar dari bandara. Untuk jalur kuning hanya dilakukan penelitian dokumen tanpa melalui pemeriksaan fisik kemudian barang tersebut langsung keluar. Untuk jalur hijau langsung keluar dan di audit dibelakang oleh pihak bea dan cukai. Penjaluran tersebut dilakukan oleh sistem kantor pusat bea dan cukai dengan memperhatikan manajemen risiko komoditi dan perusahaan.

\section{b) Mekanisme Pengawasan terhadap}

\section{Barang Keluar (ekspor)}

Pengawasan ekspor barang dilakukan oleh Seksi Kepabeanan dan Seksi Penindakan dan Penyidikan. Pengawasan pada ekspor barang telah dilakukan sesuai dengan PerDirjen Bea dan Cukai Nomor P53 /BC/2010 tentang Tata Laksana Pengawasan. Pengawasan yang dilakukan atas ekspor barang sama dengan pengawasan yang dilakukan atas impor barang yaitu melalui kegiatan intelijen, penindakan dan penyelidikan. Kegiatan intelijen yang meliputi pengumpulan informasi, pengolahan dan analisis informasi terkait dengan adanya indikasi pelanggaran kepabeanan yang selanjutnya akan ditindaklanjuti. Selain itu pengawasan juga dengan dilakukan penelitian dokumen dan pemeriksaan fisik. Salah satu jenis kasus yang terjadi adalah penyelundupan. Penyelundupan dilakukan dengan memalsukan pemberitahuan Pabean yang disampaikan kepada Kantor Pabean. Pelanggaran ini disebabkan oleh beberapa faktor antara lain masih adanya eksportir yang memanfaatkan self assesment system untuk melakukan pelanggaran, kurangnya pengetahuan eksportir tentang peraturan kepabeanan. Oleh karena itu KPPBC TMP C Mataram harus lebih meningkatkan pengwasannya agar tidak terjadi pelanggaran di bidang kepabeanan.

Berdasarkan data yang peneliti dapatkan peran pengguna jasa KPPBC TMP C Mataram pada penerimaan negara dalam bentuk penerimaan cukai, bea masuk dan lain lain dalam kurun waktu 2 tahun terakhir sangat signifikan dalam sumbangsihnya untuk pembangunan negara. Data pencapaian realisasi dan komposisi penerimaan KKPBC TMP C Mataram dari tahun 2016 hingga 2017 adalah sebagai berikut : bea masuk sebesar Rp 43.632.000.000, Cukai HT sebesar Rp 512.496.000.000, Cukai EA sebesar Rp 67.200.000.000, Cukai MMEA sebesar Rp 240.000.000.000, dan cukai lainya sebesar $\mathrm{Rp}$ 12.983.648.784. Total penerimaan bea dan cukai Mataram selama dua tahun terakhir adalah sebesar Rp 876.311.648.784. Dari keseluruhan penerimaan tersebut KPPBC TMP C Mataram didominasi dari sektor cukai hasil tembakau.

\section{Simpulan}

Kantor Pengawasan dan Pelayanan Bea dan Cukai Tipe madya Pabean C Mataram sudah melaksanakan mekanisme pengawasan lalu lintas barang baik ekspor maupun impor dengan tetap berpedoman kepada Undang - Undang dan peraturan yang terkait dengan pengawasan tersebut mulai dari penelitian dokumen, pemeriksaan fisik dan penetapan jalur terhadap barang yang melewati daerah pabean serta melaporkan hasil pengawasan kepada pusat dengan rutin. Dari data yang didapatkan dari seksi Penindakan dan Penyidikan Sepanjang Tahun 2016-2017 terdapat 3.104 penindakan. Kemudian realisasi penerimaan negara dari sektor bea dan cukai mataram yang dilihat dari pengawasan penindakan adalah sebesar $\mathrm{Rp}$ 876.311.648.784.

\section{Saran}

1. Perlunya dilakukan sosialisasi bagi importir, eksportir maupun PPJK yang baru terkait peraturan kepabeanan terkait ekspor dan impor sehingga dalam pelaksanaan pemenuhan kewajiban kepabeanan ini eksportir dan importir bisa memahami dan melakukan pemenuhan kewajiban kepabeanan sesuai dengan peraturan.

2. Perlunya kesepakatan bersama mengenai penetapan standar yang jelas terkait informasi yang dimuat dalam invoice atau packing list antara negara yang melakukan kegiatan ekspor impor. Sehingga masingmasing negara dalam melakukan kegiatan pengawasan atas kegiatan ekspor dan impor barang menjadi lebih mudah.

3. Pelatihan dan pendidikan yang diberikan kepada Pegawai atau Aparat KPPBC TMP C Mataram diharapkan lebih ditingkatkan lagi. Karena sebaik apapun sarana dan prasarana 
yang terdapat pada KPPBC TMP C Mataram tetapi tidak didukung oleh kualitas dan keterampilan SDM maka pemanfaatan sarana dan prasarana tersebut tidak akan berjalan optimal.

\section{Daftar Pustaka}

[1] Anonim.(2016). Pendapatan Negara APBN 2016. (Diakses tanggal 20 Desember 2017) dari http://kemenkeu.go.id.

[2] Bohari, H. 2012. Pengantar Hukum Pajak. Rajawali Pers:Jakarta.

[3] Hapsari,Murti ayu, Triyani. 2015. Mekanisme Pengawasan Direktorat Jenderal Bea dan Cukai Terhadap Penyelundupan Narkotika. GEMA THN XXVII: FH UNS Surakarta

[4] HR, Ridwan. 2006. Hukum Administrasi Negara. Rajawali Pers: Jakarta.

[5] Herdiansyah, Haris. 2012.Metode Penelitian Kualitatif untuk Ilmu-ilmu Sosial. Salemba Humanika: Jakarta.

[6] Helinawati, Yunita.dkk.2016.Analisis Implementasi Pengawasan Ekspor Impor Barang Pada Kppbc Tipe Madya Pabean Juanda.Jurnal Perpajakan (JEJAK)| Vol. 10 No. 1: Universitas Brawijaya Malang

[7] Moleong, Lexy J. 2011. Metode Penelitian Kualitatif. Remaja Rosdakarya: Jakarta.

[8] Miles,M.B.,A.M. Huberman, and I. Saldana.2014. Qualitative Data Analysis.Edisi Ketiga. United States of America: SAGE.

[9] Putra, Juniawan. 2009. Skripsi Mekanisme Penanganan Barang Hasil Penegahan Hingga Proses Pelelangan Atau Pemusnahan Pada Kantor Pengawasan dan Pelayanan Bea dan Cukai.Universitas Sebelas Maret:Surakarta.

[10] Ratnasari, Dewiyanti.2014. Skripsi

[11] Pelaksanaan Pengawasan Lalu Lintas Barang pada Daerah Pabean Oleh kantor Bea dan Cukai Makassar.Universitas Hasanuddin: Makassar

[12] Saidi, Muhammad Djafar. 2011. Hukum Keuangan Negara. Rajawali Pers:Jakarta.

[13] Semedi, Bambang. 2013. Pengawasan Kepabeanan. Widyaiswara Pusdiklat Bea dan Cukai:Jakarta.

[14] Siagiaan, S.P. 1980. Administrasi Pembangunan. PT. Gunung Agung: Jakarta.
[15] Situmorang, Victor. 1998. Aspek Hukum Pengawasan Melekat dalam Lingkungan Aparatur Pemerintah. Rineka Cipta:Jakarta.

[16] Sugiyono, Prof. Dr. 2017. Metode Penelitian Kuantitatif dan Kualitatif, dan R\&D. Alfabeta,cv : Jakarta.

[17] Sutarto, Eddhi. 2010. Rekonstruksi Sistem Hukum Pabean Indonesia. Erlangga: Jakarta.

[18] Sutedi, Adrian. 2012. Aspek Hukum Kepabeanan. Sinar Grafika: Jakarta

\section{Artikel/Modul/Diktat:}

[1] Undang-undang Nomor 17 tahun 2006 tentang Perubahan Atas Undang Undang Nomor 10 tahun 1995 tentang Kepabeanan

[2] Instruksi Presiden Republik Indonesia Nomor 1 Tahun 1989 Tentang Pedoman Pelaksanaan Pengawasan Melekat

[3] Peraturan Menteri Keuangan Nomor 203/PMK.04/2017 tentang Ketentuan Ekspor dan Impor Barang yang dibawa oleh Penumpang dan Awak Sarana Pengangkut

[4] Peraturan Direktur Jenderal Bea dan Cukai Nomor : Per-16/BC/2016 Tentang Petunjuk Pengeluaran Barang Impor Untuk dipakai

[5] Peraturan Menteri Keuangan Nomor 182/PMK.04/2016 tentang Ketentuan Impor barang Kiriman

[6] Peraturan Menteri Keuangan Nomor 131/PMK.01/2011 tentang Perubahan Kedua Atas Peraturan Menteri Keuangan Nomor 74/PMK.01/2009 Tentang Organisasi dan Tata kerja Instansi Vertikal Direktorat Jenderal Bea dan Cukai

[7] Direktur Jenderal Bea dan Cukai (2010). Peraturan Direktur Jenderal Bea dan Cukai Nomor P-53/ BC/2010 tentang Tata Laksana Pengawasan. 